\title{
Investigating Factors Affecting the Export of Pistachio, Saffron and Solutions to Improve Exports
}

\author{
Arash Nazemi ${ }^{1}$ \\ ${ }^{1}$ Researcher, Student Doctor of Economic Sciences, professor of Islamic Azad University and pnu, Iran \\ Correspondence: Arash Nazemi, Researcher,Student Doctor of Economic Sciences, professor of Islamic Azad \\ university and pnu, Iran. E-mail: nazemi1352@yahoo.com
}

Received: July 27, 2016

Accepted: August 18, 2016

Online Published: September 30, 2016

doi:10.5539/mas.v10n12p229

URL: http://dx.doi.org/10.5539/mas.v10n12p229

\begin{abstract}
Today, the development of non-oil exports considered a necessity, because goods export increases exchange earnings and thus guaranteeing the implementation of economic development programs is made possible foreign exchange costs and increase employment in the country for the purpose of this study is an applied research. Its aim is to investigate the factors affecting export of pistachios and saffron, field study method through questionnaires used, to determine the validity of questionnaires the expert's opinions of (Delphi), and for determination of reliability Cronbach's Alpha method is used. Population consisted of exporters of pistachios and saffron of the country. According to the test results identified factors such as laws and regulations, export of unprocessed bulk was not asked to book factories have been identified factors affecting the export of these goods.
\end{abstract}

Keywords: pistachio, saffron, solutions, hypotheses

\section{Introduction and Statement of Problem}

This article discusses the factors affecting export and trade pistachios and saffron, as well as the rules and regulations governing the export of non-oil. Exports are a debate that has preoccupied the minds of many trade officials, especially over the past decade, in order to get rid of oil revenues, this issue is more important. However, non-oil exports from fluctuations in recent years have been great. Jump in oil prices in late 1352 and 1353 and reduce restrictions on oil exports and non-oil exports in 1361 increased revenue was unpopular. Foreign trade is an important issue in country's economic development. This source of revenue for attracting investment and new technologies in order to increase the country's generating capacity (Abrishami, 1996). Classics believe that trade for extended domestic market, division of labor, increase efficiency, and improve productivity, growth, economic development, and acts as an engine of economic growth and development (M. Mir, 1999). Iran's foreign trade with the single export product and the heavy dependence on hard currency earnings from oil exports is known. Since the discovery of oil in Iran to date has been increasing export share of total exports. In addition, exports in recent decades, especially after the Islamic Revolution of Iran has always been associated with fluctuations remarkable and the economy is faced with a serious crisis.

The need to avoid and get rid of its problems single-product exports, diversify export products, the foreign exchange for investment and increasing share in global trade and international markets, clearly shows the importance of non-oil exports. Non-oil exports in economic activity and its effect on the economy of special importance and relative growth has been undeniable but because seriously and not considered appropriate in the form of planning is not optimal, desired result is not achieved in the country's economic development approach (Akbari et al., 2000). In Iran during the period studied agricultural exports in 1341-1999 on average 40 percent of the country's exports. By strengthening this part of the side of a country's self-sufficiency in the production of some strategic and proceeds from the issuance of these products on the other hand intake was significantly improved. So we can learn from the country's agricultural sector as a business unit pills or the important advantages and characteristics such as variety of climate, ideal temperature variations land, cheap labor, close to half the population context of economic activity, less dependence on technology complex and expanding production facilities. Essentially requires the formation of a strong part in the end, the appropriate policies. These policies cannot be implemented without identification of the most effective factors. Therefore, in order to strengthen the agricultural sector and increase exports this section, determine the factors affecting the export of 
agricultural products is something essential.

In the field of export of agricultural supply behavior and its determinants have been done under some of them are mentioned:

Mirzaee Akhijhani on factors affecting the supply of agricultural commodities and traditional exports has studied and has concluded that price and income elasticity of supply of agricultural exports and traditional, smaller than unity. In other words, the supply of traditional exports in the agricultural sector and export relative price and income elasticities suppliers of exports is low (Mirzaee Akhijhani, 1992). Fotros in their study titled "The effect of the government's monetary and fiscal policy variables and major agriculture "to the conclusion that fiscal policy did not have a significant effect on agricultural exports but government monetary policies, especially exchange-rate policy (massive devaluation of the rial against foreign currencies), and remarkable positive effect on increasing agricultural exports has (Fotros, 1996).

Good luck in the study have shown that the relative price index of agricultural export supply, the shock of the supply of agricultural products, domestic demand pressure deviation from the equilibrium real exchange rate. Index of exchange rate volatility and time trends have a significant effect on the supply of agricultural exports among the estimated coefficients, supply shocks or sudden changes in crop producing has most effect (Nik Eghali, 1999)

The present study is to answer the following questions:

The present study is to answer the following questions:

1) What factors affect the supply to affect exports?

2) Rules and regulations affect their exports?

The research hypotheses are:

1) There is a significant relationship between the desired production and export of these products.

2) There is a significant relationship between the administrative hierarchy (bureaucracy) and the rules and regulations of non-oil exports, exports of goods.

3) There is a significant relationship between not affiliated factories for processing and packaging of pistachios and saffron and prevent the sale of the bulk of the exports of these products.

4) There is a significant relationship between the administrative hierarchy (bureaucracy) and the rules and regulations of non-oil exports, exports of goods.

5) There is a significant relationship between not affiliated factories for processing and packaging of pistachios and saffron and prevent the sale of the bulk of the exports of these products.

\section{Research Methodology}

In view of the subject content and research direction in this situation or phenomenon, as has been well studied and described;

We can say that the method of research is descriptive and also according to the study of cognition and rank the factors affecting the length of time the implementation of development projects; in terms of the relationship between variables and classification according to Rozentan and Rozno (1984) of the study is correlational research. From the perspective of the purpose and nature, given that research to develop the knowledge to use in a particular field executive in the province of applied research is considered.

\subsection{Applied Research}

On the basis, the research was divided into basic and applied research. Of course, Zohreh Sarmad believes based on objective divided into three categories: basic research, applied research, research, and development. The following comments can be said with regard to research and development is an applied research. Applied research is research that uses basic research findings to improve and integrity in the behavior, methods, tools, equipment, products, structures and patterns can be used in human communities. Applied research aimed at the development of practical knowledge in a particular field (Hafeznia, 2003).

\subsection{Correlational Research}

In this type of relationship between variables is based on objective analysis. In solidarity, if research is to predict the dependent variables based on independent variables and the dependent variable independent variable to predict the dependent variable says. The distinctive feature of this experiment is to study the correlation between the independent variables are not manipulated. Based on objective into two main categories: 
1. The correlation between the two variables: the relationship between two variables change the degree of synchronization variables other words. Most of the research on the correlation between two variables, the default interval scale with normal distribution and Pearson correlation coefficient is used. Example: there is a relationship between documents path of stability and successful performance.

2. Regression analysis: regression analysis to predict one or more variables predictive criterion based on one or more variables. If the purpose of investigating a criterion variable is a predictor of regression was used. If the study is to predict a dependent variable based on a multiple regression, analysis is used. If several criteria based on the number of predictor variables can be analyzed and used multiple regression (Hafeznia, 2003).

\subsection{Population, Sample Size and Sampling}

The population of the entire group of people, events or things implies that the researcher wants to investigate it. The population should be defined inclusive; this means that the definition should be expressed so that the standpoint of the time and location of all units of study include and yet, people are not that common traits, distinctive and prevent them study (Gorgi, 2010).

Due to the nature of the study, the study population included all active in the field of pistachios and saffron exporters have been active in the study of random sampling method for sampling and live. In addition, to collect information from the survey, the sampling using a sample of the population is taken. The study identified the different sectors and at each sample was performed using Morgan table. Obviously, the number of people in proportion to the number of employees in each department was doing. To determine the sample size, according to the analysis of small sample groups may contain unstable, it is also likely to lead to misleading results, relatively large sample size and the number (306) of the population was considered. it is therefore possible to calculate the required sample size is representative of the community of formula (Equation 1) was used as follows:

Equation Number (1) - Cochran formula

$5 \%=\mathrm{d}$ error confidence level of $95 \%(1.96) 1=\mathrm{t}$

The statistical population $=\mathrm{N}$, sample size $=\mathrm{p}$, Statistics absence of trait adjectives $=\mathrm{q}=$

$$
\begin{aligned}
& \mathrm{N}=\longrightarrow \quad \mathrm{D}^{2}(\mathrm{n}-1)+\mathrm{t}^{2} \mathrm{pq} \\
& \mathrm{N} \\
& \begin{array}{lllllll}
(1 / 96)^{2} & 0 / 5 & 0 / 5 & 150 & \\
0 / 0025 & 149 & (1 / 96)^{2} & 0 / 5 & 0 / 5
\end{array}
\end{aligned}
$$

Sampling, selection process and the number of members of the community, so that research by examining a sample and understand the characteristics or properties of the samples, the community will be able to generalize the characteristics or attributes to elements (Danaee F. et al., 2010).

How physically distributing questionnaires among executive agencies and electronic distribution with a request the supreme audit court of auditors distributed and collected. Each pre-determined number of employees and the questionnaire (sample size in proportion to the number of community members) in proportion to the number of employees per unit was distributed between them.

\subsection{Methods and Tools for Data Collection}

The data collected in this research is a combination of the library and field.

1 Library: in the research a library methods used in this study, the researchers collected literature and record the subject of Persian and Latin library resources, articles, books and from the World Wide Web and results of their studies at the appropriate tools such as forks table and form, recorded and at the end of the action classify and exploit them

2. Field Research: Athletics methods refers to methods to collect data the researcher has no choice but to go outside and referring to people or the environment and communicate with the unit of analysis: individuals (in this study), to collect information they need.

\section{The Data Collection Tool}

Data collection tools in this study were a questionnaire. In addition, a questionnaire was used to collect data. The questionnaire consisted of 5 variables and 10 are self-made, prepared then with the help of supervisors and poll of a number of scholars and experts, is complete and final. Inventory, factors affecting the length of time to 
assess the implementation of development projects. The questionnaire has 44 questions that measured the total ..... 10 components. To collect the data in this questionnaire are closed standard used in the preparation of valid questionnaires and according to the assumptions and objectives of the questions and the options they have been used.

In order to evaluate and analyze the variables related to the research that was discussed in the literature and finally, a questionnaire to assess factors affecting delay the implementation of construction projects in total (306) questionnaires were distributed among the sample.

This questionnaire after the validity and reliability (according to Table 2, in the sample studied Likert scale is used to measure data (Ganji, 2001). In this case, the qualitative characteristics to slightly transformed, the statistical analysis carried out on the basis of quantitative properties. To convert qualitative to quantitative characteristics of the questionnaire for each of the options numerical values as Table 1 is applied. After collecting the questionnaires, rating each question a calculation and then conducted a statistical analysis of the results obtained.

Table 1. Numerical value options questionnaire

\begin{tabular}{|c|c|c|c|c|c|c|}
\hline No questions & $\begin{array}{c}\text { No } \\
\text { questions }\end{array}$ & $\begin{array}{l}\text { Very } \\
\text { low }\end{array}$ & Little & Somewhat & $\begin{array}{c}\text { Much } \\
\mathrm{m}\end{array}$ & $\begin{array}{l}\text { Very } \\
\text { much }\end{array}$ \\
\hline $\begin{array}{l}\text { Identify factors affecting delay the } \\
\text { implementation of construction projects }\end{array}$ & 1 & & & & & \\
\hline
\end{tabular}

\subsection{Validity and Reliability}

In quantitative research instrument must be both technical reliability and validity

A) Reliability

The concept states that the reliability of the instrument under similar conditions to what extent gives the same results. Ebel \& Frisbie reliability of the correlation between a set of grades and another set of scores obtained in a test is equivalent to define (Wiersma and Jurs, 1990). In quantitative research to calculate the reliability of techniques such as Test - Retest, Equivalence, Split - half, Kuder-Richardson and Cronbach's alpha method and other methods are used. The reliability of the measurement process only applies to the extent it is no random error. Stable reliability, accuracy and predictability findings considered (Ebrahimi et al., 2011).

B) Validity

The concept states that the validity of the measurement instrument measures the extent to which characteristics and attributes. Without the knowledge of validity, measurement tools carefully the data from the tool cannot be sure. There are several methods that can be measured to determine the validity content validity, criterion validity, constructs validity mentioned (Abedi \& Shavakhi, 2010). Construct validity involves understanding the theoretical rationale that underlies the standards are derived. The way it works is as follows. So that the structure in question relate to other structures arise theoretical framework for marketing phenomenon. As the construct validity of the predicted correlation between the target and related structures is more. Content validity of subjective judgment expert is about the appropriateness of the measure (Ebrahimi et al., 2011).

Table 2. Case Processing Summary

\begin{tabular}{c}
\hline $\mathrm{N} \%$ \\
\hline Valid $^{2} \quad 306100.0$ \\
CasesExcluded $^{\mathrm{a}} \quad 0 \quad .0$ \\
Total $\quad 306100.0$ \\
\hline
\end{tabular}

Note. a. Listwise deletion based on all variables in the procedure.

Table 3. Reliability Statistics

\begin{tabular}{cc}
\hline Cronbach's AlphaN of Items \\
\hline .861
\end{tabular}




\subsection{Methods of Data Analysis}

In this study was to analyze the data collected would be used descriptive and analytical statistics.

\subsection{Descriptive Statistics}

Descriptive statistics for demographic data and other data for tables, indexes central, charts will be used and the percentage of spss software.

\subsection{Inferential Statistics}

Spss statistical software to analyze data collected from a sample of the questions will be used; for the answer to that variance analysis is a statistical method used. Analysis of variance analyzes differences between categorical variables or differences between the two. Here we used a sample or analysis of variance we use. ANOVA way in which the effect of an independent variable on the dependent variable is evaluated. Default key to this technique is that two or more samples of the population are randomly selected. The method we will use the Pearson correlation coefficient. Correlation means the two variables. When the increase or decrease in a variable with decreased or increased in other variables, the two variables correlated. Pearson correlation coefficient was used when the assumptions imply their mutual relations, Pearson correlation coefficient, and Pearson correlation coefficients. Pearson correlation coefficient (r), parametric method for normally distributed data or are used, and this factor is calculated to help fine relationship:

$$
r=\frac{\sum x y-n \overline{x y}}{\sqrt{\sum x^{2}-n \bar{x}^{2}} \sqrt{\sum y^{2}-n \bar{y}^{2}}}
$$

\subsection{Normality Test Data}

Since the normality of the dependent variable leads to the normality of residuals, be sure to model, it is normal to be controlled. Normality tests the null hypothesis and the alternative hypothesis is as follows:

$$
H_{\circ}: \text { Normal distribution of data }
$$

$H_{1}:$ Data distribution is not normal

Top of Kolmogorov-Smirnov test was used to test the hypothesis. This is less than $5 \%$ significance level test when the null hypothesis is rejected at the $95 \%$ confidence; in this study, data normalization is used from Kolmogorov-Smirnov. Due to the high fluctuation of test statistics, significance level of test data of normality assumption was confirmed.

Table 4. Normality Tests

\begin{tabular}{ll}
\hline & Data \\
\hline Test statistics & 2.516 \\
Significance level & 0.000 \\
\hline
\end{tabular}

The values shown (Figure 4-2) since a significant level, variable research is less than $5 \%$ (Sig. $<0.05$ or P- value), therefore, the null hypothesis is not rejected normality of variables. Therefore, assuming normal data confirmed stuck.

\subsection{Test Hypotheses}

To test this research in two ANOVA and Pearson correlation coefficient was used. There ANOVA significant relationship between the dependent and independent variables to be checked and examined the difference in mean and if that is confirmed by analysis of variance indicated a significant relationship between the dependent and independent variables. Moreover, to measure the direction of this relationship and the correlation between the independent variable and dependent correlation coefficient was used according to the test as the independent variable on the dependent variable and the effect will be assessed.

\section{Examination of the Hypotheses}

There is a significant relationship between the production and export of these products.

Hypothesis H0: there is a significant relationship between the desired production and export of these products. 
Hypothesis H1: there is a significant relationship between the desired production and export of these products.

According to the test result, analysis of variance to test this hypothesis (F) and low significance level (sig) indicate a significant difference between the production targets, export these products and this means that there is a significant relationship between the production targets, and export these products.

Table 5. ANOVA

\begin{tabular}{llllll}
\hline & Sum of Squares & df & Mean Square & F & Sig. \\
\hline Between Groups & 40.111 & 54 & .743 & 23.135 & .000 \\
Within Groups & 6.261 & 195 & .032 & & \\
Total & 46.372 & 249 & & & \\
\hline
\end{tabular}

To determine the effect of the independent variable on the dependent variable of the Pearson correlation coefficient was used. The test results indicate a strong positive correlation between production and marking products. The numerical value of the Test statistics show 0.816 that nearly one whose positive and indicate a strong correlation between the production and export of products, and 0.000 test with a significant level of less than 0.5 . Therefore, the null hypothesis is rejected and the hypothesis has been approved.

Table 6. Pearson correlation coefficient

\begin{tabular}{ll}
\hline Significance level & Statistics \\
\hline .000 & $.816^{* *}$ \\
\hline
\end{tabular}

\subsection{The Second Hypothesis Test}

There is a significant relationship between the administrative hierarchy (bureaucracy) and the rules and regulations of non-oil exports, exports of goods.

The hypothesis H0: There is not a significant relationship between the administrative hierarchy (bureaucracy) and the rules and regulations of non-oil exports, exports of goods.

Hypothesis $1 \mathrm{H}$ : There is a significant relationship between administrative (bureaucracy) and the rules and regulations of non-oil exports, exports of goods. According to the test result analysis of variance to test this hypothesis, (F) and low significance level (sig) indicated that there were significant differences between the administrative hierarchy (bureaucracy) and the rules and regulations of non-oil exports, exports. When considering the results of variance analyzes can be concluded there is a significant relationship between the administrative hierarchy (bureaucracy) and the rules and regulations of non-oil exports, exports of goods.

Table 7. ANOVA

\begin{tabular}{llllll}
\hline & Sum of Squares & df & Mean Square & F & Sig. \\
\hline Between Groups & 14.988 & 13 & 1.153 & 8.669 & .000 \\
Within Groups & 31.384 & 236 & .133 & & \\
Total & 46.372 & 249 & & & \\
\hline
\end{tabular}

To determine the effect of the independent variable on the dependent variable of the Pearson correlation coefficient was used and the test results indicate a strong positive correlation between marking an administrative bureaucracy and export laws and regulations by exporting non-oil commodities. Test statistics show 0.514 that the positive number whose value represents a moderate correlation between these two variables.

Table 8. Pearson correlation coefficient

\begin{tabular}{ll}
\hline Significance level & Statistics \\
.000 & $.514^{* *}$ \\
\hline
\end{tabular}




\subsection{The Third Hypothesis Test}

Hypothesis: there is a significant relationship between the lack of factories for processing and packaging of pistachios and saffron and prevent the sale of bulk exports of these products.

The hypothesis H0: there is no significant relationship between the lack of affiliated factories for processing and packaging of pistachios and saffron and stop selling the bulk of exports.

Hypothesis H1: there is a significant relationship between not affiliated factories for processing and packaging of pistachios and saffron and prevent the sale of bulk exports of these products.

According to the test result analysis of variance to test this hypothesis (F) and low significance level (sig) show that there was no significant difference between the affiliated factories for processing and packaging and stop selling the bulk of pistachios and saffron exports of these products and the hypothesis is confirmed.

Table 9. ANOVA

\begin{tabular}{llllll}
\hline & Sum of Squares & df & Mean Square & F & Sig. \\
\hline Between Groups & 15.235 & 14 & 1.088 & 8.213 & .000 \\
Within Groups & 31.137 & 235 & .132 & & \\
Total & 46.372 & 249 & & & \\
\hline
\end{tabular}

To determine the effect of the independent variable on the dependent variable of the Pearson correlation coefficient was used. The test results indicate that a strong and positive correlation between absence due to packing and processing plants with non-oil exports of the product. The numerical value of 0.553 indicates that the Test statistics is positive which indicates a moderate correlation between these two variables.

Table 10. Pearson correlation coefficient

\begin{tabular}{cc}
\hline Significance level & Statistics \\
\hline .000 & $.553^{* *}$ \\
\hline
\end{tabular}

\section{Suggestions}

In total, according to the results of this study can be said that due to the relatively significant distance between suppliers and producers of pistachios, the ultimate provider of export supply are key variables in the short run most desirable export supply will not help. Accordingly, in order to influence policies, particularly in the field of exchange rates, the following suggestions are offered:

1. Given that the distance between producers and exporters of pistachio greater possibility of transferring the effects of macroeconomic policies (which is taken to encourage exports) will be lower, it is suggested that as much as possible pistachio export units are made up of pistachio producers. This would speed up the response of monetary policy is export.

2. Policies provide clear information on future trends affecting the supply to manufacturers or suppliers of export subsidies.

3. According to influence decisions pistachio producers from fluctuations in currency rates and that ultimately these decisions affect the supply of export, it is suggested that to improve the quality and supply manufacturing organizations to take effective measures pistachio producers.

\section{References}

Abrishami, H. (1996). The economy of Iran, Scientific and Cultural Publications (1st Ed.), Tehran.

Akbari, M. R., \& Hossein, K. H. (2000). The impact of exports on economic growth and capital formation. Journal of Planning and Budget, 52-53, pp. 63-84.

Central Bank of the Islamic Republic of Iran. (1999). The wholesale price index circle, the wholesale price index.

Central Bank of the Islamic Republic of Iran. (2000). Forty years of National Accounts 1338-77.E 
Central Bank of the Islamic Republic of Iran. (2001). The balance sheet and economic reports.

Fotros, M. H. (1996). The effects of fiscal and monetary policies of the major variables agriculture (1350-70). A collection of papers of the Conference of Agricultural Economics, 1, Sistan and Baluchestan University Press, pp. 213-249

Gujarati, D. (1999). The foundations of econometrics. A. Hamid (Trans.), Tehran University Press (2nd Ed.), Tehran.

Josephi, D. (2000). And estimate the total import demand by the technique of convergence, graduate thesis. School of Economics and Political Science, Shahid Beheshti University.

Mir, G. (1999). The fundamental issues of development economics. In G. H. Azad (Ed.), Reed Publishing, Printing, Tehran.

Mirzaee, A. H. (1992). Econometric analysis of factors contributing to the development of non-oil exports of Iran. Thesis, Master of Science, Faculty of Humanities. Tarbiat Modarres University.

Mortazaei, Z. M. (1999). Examining the effect of uncertainty of exchange rate fluctuations on exports, graduate thesis. School of Economics and Political Science. Shahid Beheshti University.

Nick, I. S. (1999). The effects of exchange rate fluctuations and deviations from the equilibrium real exchange rate on the supply of agricultural exports, graduate thesis. School of Economics and Political Science, Shahid Beheshti University.

Noferesti, M. (1999). Unit root and co-integration in econometrics, Rasa Institute of Cultural Services, Printing, Tehran.

\section{Copyrights}

Copyright for this article is retained by the author(s), with first publication rights granted to the journal.

This is an open-access article distributed under the terms and conditions of the Creative Commons Attribution license (http://creativecommons.org/licenses/by/4.0/). 